or at least to spread only on very concentrated salt solutions. Below are given the areas in sq.m. per mgm. occupied by these different globulins. Theso figures are simply intended to show how the surface concentrations are comparable with those found for the ordinary proteins.

Areas in sq. metre per mgm. under $1 \mathrm{dyne} / \mathrm{cm}$.

\begin{tabular}{|c|c|c|c|}
\hline $\begin{array}{l}\text { Dizt. water } \\
\text { HCl N/,000 }\end{array}$ & $\begin{array}{c}\text { Myosin } \\
0.9 \\
1.1 \\
1.6\end{array}$ & $\begin{array}{c}\text { Amandin } \\
0.9 \\
1.3 \\
1.1\end{array}$ & $\begin{array}{c}\text { Edestin } \\
0 \cdot 7 \\
0 \cdot 9 \\
1 \cdot 3\end{array}$ \\
\hline
\end{tabular}

A substance may have a very low spreading pressure and yet be spread and give a film stable under relatively high pressures. It has to be emphasized that, with substances that do not spread spontaneously, one of the functions of the solvent is to disperse the molecules over the largest possible area. It is found that to obtain complete scattering, it is necessary to ensure that the concentration of the protein in the drop should bo below a certain quantity, just as is the case with solutions of stearic acid or tristearin in a volatile solvent and gliadin in alcoholic solution ${ }^{3}$.

The 'spreading number'. It has often been noticed that the spreading of a protein from a crystal is more difficult, if not impossible (for example, casein), at the isoelectric point. This is to be expected since at that point the solubility is at the minimum and, therefore, the work of adhesion being also a minimum, the spreading pressuro is lower. This variation of the spreading pressure with the $p H$ seems to be in contradiction with the results of Gorter and collaborators, who found a maximum of the 'spreading number' at the isoelectric point, when the protein was injected as a solution. 'The contradiction is only apparent and is due to the bad definition of 'spreading'. The point in question is rather the spreading efficiency: Gorter's curves showing the 'spreading number' as a function of the $p \mathrm{H}$ or the salt concentration are three-dimensional solubility curves and do not represent a surface phenomenon. In reality, if the substrate's $p H$ corresponds to the isoelectric point of the protein, this, being at its minimum solubility, will spread before an appreciable quantity has time to dissolve. At other $p \mathrm{H}$ or salt concentrations, it will be more or less soluble and the surface concentration will correspond only to the part of the protein which is left on the surface.

In order to show that the variation of the 'spreading number' with the $p \mathrm{H}$ is in any case not a surface phenomenon, experiments have been made in which the $p \mathrm{H}$ of the substrate was changed under the monolayer, after this had been formed and the state of equilibrium reached". A layer of egg albumin was spread by the Gorter and Grendel technique on $p H 4.9(M / 1,000$ acetate buffer $)$. The $p H$ of tho sub. strate was afterwards brought successively to $p H \mathbf{H} 3 \cdot 2$, $5 \cdot 1,2 \cdot 6$, then back to $4 \cdot 9$ and 11 . The order of succession is immaterial: in one case, the film was spread on $p \mathrm{H} 7.8\left(\mathrm{M} / 1,000 \mathrm{Co}_{3} \mathrm{HNa}\right)$ with the new technique and the $p \mathrm{H}$ afterwards brought to 4.9 . The observel areas under $1.5 \mathrm{dyne} / \mathrm{cm}$. are given below, the value 100 being arbitrarily attributed to the area at $p \mathrm{H} 4 \cdot 9$.

\begin{tabular}{|c|c|c|c|}
\hline \multicolumn{4}{|c|}{ Egg albumin (relative areas under 1.5 dyne' $\mathrm{cm}$.) } \\
\hline$p \mathrm{HI} \quad \begin{array}{l}4.9 \\
9\end{array}$ & 100 & & \\
\hline $5 \cdot 1$ & 100 & $n$ & \\
\hline $2 \cdot 6$ & 103 & 4.9 & 100 \\
\hline 4.9 & 100 & & \\
\hline
\end{tabular}

If Gorter's curve represents the change of area occupied by a given quantity of egg albumin, the passage from $p \mathrm{H} 4.9$ to 3.2 would have reduced the area to one eighth. Likewise, the film should extend 20 or 30 times by changing the $p H$ from $7 \cdot 8$ to $4 \cdot 9$. Whereas in fact, as can be seen by the numbers above, the maximum variation in the area is at the most 10 per cent and the area is not even at a maximum at the isoelectric point. As noted by Philippis, a study of the complete isotherm shows that these relatively small variations in the area are entirely attributable to changes of the compressibility.

A more detailed account will be published elsewhere.

\section{Laboratory of Colloid Science,}

\section{Dervichian.} Cambridge.

August 16.

1 Proc. Roy. Soc., A, 137, 62 (1932):

2Trans. Farad. Soc., 22, 477 (1926).

Sec Mitchell, Trans. Farad. Sac., 33, 1130 (193i).

- There is in fact a 're-extension' surface phenomenon which occurs in certain circumstances: sce, Dervichian, D., C.R., 209, 16 (1939).

-Philippl, "On the Nature of Proteins". Thesis, p. 71 (Amsterdam. $1936)$.

\section{Comparison of the Adsorption, Electrolytic, and} Interference Methods of Measuring Film Áreas

THe Bowden-Rideal ${ }^{1}$ electrolytic method of mensuring area by the electrodeposition of hydrogen ions on conducting surfaces has been modified so that rapid measurements may bo made by using audiofrequency alternating currents superposed on very feeble direct currents, and measuring directly the alternating changes of electrodo potential with an amplifier and wavo analyser with ono megohm input impedance. Comparisons of surface areas were made by measuring the alternating current required to give the same alternating electrodo potential as on one square centimetre of a mercury surface.

Measurements of the same surface were also made by the interference method ${ }^{2}$.

Finally, the adsorption of palmitic acid was studicd on large metallic granules with activated metallic surfaces, and when covered with coloured oxide films. The electrolytic method was also used with theso granules. The results of adsorption measurements are near those of the interference method for slightly oxidized surfaces, but approach the order of magnitude of the electrolytic method for metallic surfaces.

A full account of the work will bo published later.
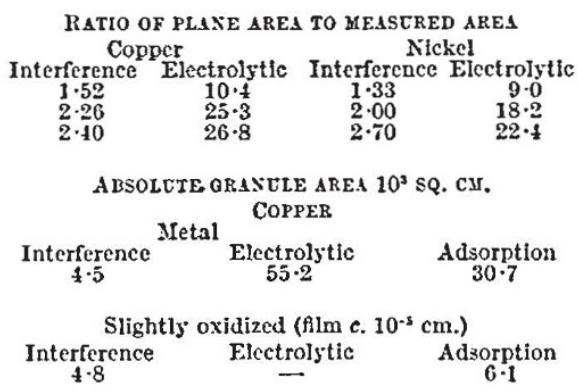

Faculty of Engineering,

Fouad El Awal University, Giza.

2 Proc. Roy. Soc., A., 120, 89 (1923), et $8 e q$.

'Constable, Proc. Roy. Soc., A., 119, 196 (1923). 